\title{
К ВОПРОСУ О МЕТОДИКЕ ОПРЕДЕЛЕНИЯ ТЕПЛОВЫХ КОЭФФИЦИЕНТОВ ВЛАЖНЫХ МАТЕРИАЛОВ
}

\author{
А. Алумяэ, \\ кандидат технических наук
}

\begin{abstract}
Максимальное внедрение новых строительных материалов, всемерное облегчение конструктивных элементов зданий, повышение общей экономической эффективности строительства в нашей стране должны сопровождаться также улучшением жилищно-бытовых условий советских людей. Решение этой задачи требует от строительной теплофизики разработки новых методов испытания и применения новых приборов для дальнейшего усовершенствования методов теплотехнического расчета зданий. Существенное значение в этих расчетах имеет правильный выбор значений тепловых коэффициентов материалов.
\end{abstract}

Поскольку коэффициенты теплопроводности и температуропроводности обычно сильно зависят от влажностного состояния материалов, необходимо проводить определения этих коэффициентов с учетом реальной влажности последних и на приборах, обеспечивающих правильность учета, а также пользоваться этими коэффициентами при теплотехнических расчетах ограждающих конструкций в соответствии с реальной влажностью материалов в условиях эксплуатации ограждения.

Таким образом, одной из основных проблем, от которой зависит повышение точности теплотехнических расчетов, является изучение влияния влажности на величину тепловых коэффициентов. Для расчета сопротивления теплопередаче ограждающих конструкций при любой фактической влажности материалов проектные организации используют приведенные в СНиП значения тепловых коэффициентов при нормальной влажности материалов. При этом нередко обнаруживается неудовлетворительное состояние ограждений в эксплуатации, хотя по расчетным значениям конструкция должна удовлетворять требованиям. Происходит это в основном из-за значительного отклонения значений тепловых коэффициентов от приведенных в СНиП, вызванного увлажненным состоянием материалов. В то время как кирпичные стены достигают нормальной влажности уже после $1-2$ лет эксплуатации, многие новые материалы высыхают очень медленно. Это необходимо учитывать уже при проектировании и принимать для расчетов теплопередачи такие значения тепловых коэффициентов, которые соответствуют фактическому влажностному состоянию материалов при возведении зданий.

Для получения достоверных значений тепловых коэффициентов экспериментальным путем необходимо разработать такую методику определения их, которая обеспечивала бы условия, близкие к условиям работы этих материалов в конструкциях. С этой целью необходимо отработать методику определения перепадов температур в образцах при проведении эксперимента.

В настоящее время считается установленным, что во влажных телах процессы теплообмена и влагообмена органически взаимосвязаны. Термические коэффициенты 
влажных материалов должны рассматриваться как величнны эквивалентные, т. е. как такие величины, которые одновременно отображают не только процесс переноса тепла, но также и процесс переноса влаги.

Исходя из высказанного А. В. Лыковым ['] положения о том, что эквивалентный коэффициент теплопроводности близок к инстинному только в том случае, если критерий $L u{ }^{\star}$ много меньше единицы и критерий теплопроводности, т. е. отношение эквивалентного коэффициента теплопроводности к истинному, прямо пропорциона. лен критерию $L u$, для исследования выбирались материалы по возможности с раз. личными значениями $L u$.

Опыты проводились со следующими материалами: кварцевым песком $(L u=0-1,5$ при влажности $0-20 \%)$, в котором при высоких влажностях распространение влаги опережает распространение тепла; ячеистыми бетонами, у которых критерий $L u$ меньше единицы и, стало быть, поле температур опережает по фазе поле удельных влагосодержаний; опилками, у которых критерий $L u$ значительно меньше единицы, в связи с чем определенный опытным путем коэффициент теплопроводности их должен быть близок к истинному.

При выборе методики эксперимента надо учитывать необходимость достижения начального равномерного распределения влаги внутри материала и сохранения возможно более полного постоянства этого состояния в течение опыта.

Для уменьшения возможности перераспределения влаги в образ. цах во время опыта необходимо, чтобы градиенты влажности отсутствовали, а градиенты температуры были минимальными.

Применение методов стационарного теплового потока не дает достоверных данных, поскольку любой из этих методов по самой своей идее требует создания и поддержания в течение длительного времени градиентов температуры внутри образца испытываемого материала, а они, в свою очередь, неизбежно вызывают перераспределение влаги в образце. Если в начале испытания образец равномерно увлажнен, то к концу увлажнение становится резко неоднородным. Влага в процессе опыта перемещается от нагретых мест к холодным и там накопляется.

Таким образом, для испытаний влажных материалов более пригодны методы нестационарного теплового потока. Однако, применяя их, следует создавать небольшие градиенты температуры в испытываемом материале и проводить опыт в очень короткие сроки. Незначительные градиенты температур снижают скорость перераспределения влаги, и образец остается практически равномерно увлажненным.

С другой стороны, проведение опытов при незначительных градиентах температуры ухудшает их воспроизводимость, что приводит к уменьшению точности результатов. Происходит это из-за того, что различные внешние влияния приобретают больший вес. Например, если создать внутри образца градиент температуры ниже одного градуса на сантиметр, то изменение температуры окружающей среды на $0,1^{\circ}$ уже сказывается на результатах опыта. Поэтому необходимо экспериментальным путем найти оптимальные режимы проведения опыта, т. е. найти оптимальные значения градиентов температур, которые не вызывают заметной миграции влаги и в то же время дают достаточную точность и повторяемость опытов без усложнения усло-

* $L u=\frac{a^{\prime}}{a}-$ критерий инерционности поля потенциала влаги по фтношению к полю потенциала тепла, 
вий. их проведения. Очевидно, что оптимальные режимы зависят от материалов и не являются одинаковыми для всех видов их. Следовательно, для конкретных материалов надо найти свои оптимальные режимы эксперимента.

Учитывая вышеизложенное, в основу методики опытов были положены методы регулярного режима, разработанные Г. М. Кондратьевым $\left[{ }^{2}\right]$ и его учениками, основанные на возбуждении в исследуемом теле нестационарного поля температур. Достоинством этих методов является: разработанность теории, простота измерительной аппаратуры и методики проведения опытов, малая длительность эксперимента. Опыты проводились на цилиндрических образцах диаметром 50 мм и высотой 100 мм, заключенных в латунные оболочки с никелированной поверхностью. В качестве эталона был использован алюминиевый цилиндр тех же размеров, заключенный в аналогичную оболочку.

Измерителями температуры служили медно-константановые термопары, показания которых регистрировались зеркальными гальванометрами типа M-21.

Термопары заделывались в образцы гипсом, а в эталон - сплавом Вуда. Все исследуемые материалы предварительно высушивались в сушильном шкафу при температуре $105-110^{\circ}$ до постоянного веса. Затем цилиндры с прикрепленными к ним термопарами закладывались в оболочки и герметически закрывались. Благодаря герметичным оболочкам выдерживание цилиндров при определенной влажности не представляло трудностей.

Увлажнение сыпучих материалов до определенной влажности производилось добавкой необходимого количества воды с последующим тщательным перемешиванием всей массы и заполнением ею оболочек-калориметров, которые снова плотно закрывались и выдерживались при комнатной температуре в течение недели. Кусковые материалы увлажнялись путем накапывания необходимого количества воды на образец с последуюшей выдержкой в герметически закрытых калориметрах примерно в течение 10 дней для выравнивания влаж: ности. Время выдержки образцов определялось предварительными опытами с аналогичными материалами, причем через определенные промежутки времени образцы разрезались и высушивались для установлення сроков выравнивания влажности.

Чтобы выяснить влияние градиента температуры на перераспределение влаги в различных материалах, опыты проводились при двух начальных градиентах температуры в образце $\nabla t=0,8$ и 8 град/см.

Сперва опыты проводились при $\nabla t=0.8$ град/см как в ламбдакалориметре, так и в акалориметре, причем в последнем проводилось по три опыта в каждом цикле. Опыты при $\nabla t=0,8$ град/см проводились для каждой влажности дважды два дня подряд. Нагревание образца при этом производилось теплом руки до температуры, которая отмечалась показаниями термопар, подключенных к зеркальному гальванометру.

На третий день проводились опыты при $\nabla t=8$ град/см. Для этого образец нагревался в термостате при температуре $40^{\circ}$ в течение одной ночи, после чего измеряли темп его охлаждения в камере спокойного воздуха вместе с эталоном. Для опытов в акалориметре образцы нагревали в горячей воде.

Повторный опыт при $\nabla t=8$ град/см (для создания возможности выравнивания влажности в образце) проводился через 48 часов. По окончании опыта к образцу добавлялось необходимое количество 
воды, после чего он выдерживался в течение 7-10 дней при комнатной температуре и опыт начинался сначала.

Многократные повторные опыты в акалориметре, двухкратные опыты в ламбдакалориметре при небольших интервалах влажностей дали возможность получить довольно много точек, что служит предпосылкой для достижения большей точности. При расчете $\lambda$ по данным коэффициента температуропроводности в акалориметре использовалась удельная теплоемкость $(c)$, определенная по аддитивной формуле.

Результаты свыше 100 серий определений по методу регулярного режима с различными материалами при различной влажности представлены на фиг. 1. Графики составлены по усредненным значениям двух образцов по двукратному наблюдению охлаждения в камере спокойного воздуха и шестикратному определению охлаждения в акалориметре. для каждой влажности и начального перепада температур.

Анализ приведенных зависимостей $a=f_{1}(w)$ и $\lambda=f_{2}(w)$ показывает, что повышение влажности приводит у всех материалов к повышению коэффициента теплопроводности, в то время как коэффициент температуропроводности либо сначала повышается и потом уменьшается (песок), либо практически все время уменьшается (опилки), либо сохраняет постоянную величину (пено- и газокукермит при малых начальных градиентах температуры).

На основании приведенных графиков исследуемые материалы можно разделить на три группы.

1. Изменение коэффициентов тепло- и температуропроводности при различной влажности не зависит от величины начального градиента температуры (кварцевый песок) (фиг. 1a). Коэффициент температуропроводности сначала быстро увеличивается, а после достижения $4 \%$ весовой влажности начинает постепенно уменьшаться. Так же обстоит дело с коэффициентом теплопроводности. В начале кривая нмеет крутой подъем, а по достижении коэффициентом температуропроводности максимума дальнейший рост коэффициента теплопроводности замедляется. Таким образом, на кривой температуропроводности имеется одна сингулярная точка, которой соответствует свое критическое влагосодержание.

Аналогичные кривые получили также М. Ф. Казанский и А. Н. Куландина $\left[{ }^{3}\right]$, которые объясняют такой ход кривых изменением форм связи влаги с материалом. Происходящее при увлажнении тела поглощение адсорбируемой влаги (влага физико-химической формы связи) не приводит к значительным изменениям тепловых коэффициентов. Интенсивный рост коэффициентов температуро- и теплопроводности в капиллярно-пористых телах связан с началом капиллярной конденсашии влаги в микропорах и продолжается вплоть до появления в макропорах тела капиллярной влаги, которая удерживается в пористом теле капиллярными силами и относится к влаге физико-механической формы связи. Дальнейшее поглощение телом капиллярной влаги приводит к относительно слабому росту коэффициента теплопроводности и уменьшению коэффициента температуропроводности.

Характер кривых (фиг. 1 ) п) показывает, что при определении тепловых коэффициентов для песка нельзя пренебречь влиянием влагообмена при теплообмене. Поэтому при любых методах определения получаемые коэффициенты тепло- и температуропроводности являются эквивалентными. Объясняется это явление тем, что в данном случае инерционность полей температуры и влагосодержания одинаковая, т. е.

6 TA Toimetised T-2 61 
$L u=1$. Поэтому при опытах с материалами этой группы не имеет смысла добиваться небольших градиентов температуры в начале опыта, которые всегда в некоторой мере уменьшают точность определений.

2. Изменение коэффициентов тепло- и температуропроводности с повышением влажности хотя и зависит от начального градиента температуры, но характер изменения кривых при обоих градиентах температуры одинаков (древесные опилки) (фиг. 1б). Коэффициент температуропроводности при малом начальном градиенте температуры сначала уменьшается быстрее, чем при большом. При весовой влажности выше $80 \%$ обе кривые убывают с одинаковой быстротой. Аналогично коэффициент теплопроводности имеет до $80 \%$ весовой влажности более крутой подъем, особенно при большем градиенте. После $w_{\text {в }}=80 \%$ возрастание коэффициента теплопроводности с повышением влажности значительно уменьшается и при малых градиентах остается практически постоянным. Из литературных данных [1] следует, что точка перегиба на кривой температуропроводности соответствует максимуму термоградиентного коэффициента. Это также указывает на то, что в точке перегиба происходит изменение формы связи влаги с материалом.

Характер кривых (фиг. 16) показывает, что при обоих градиентах влияние влагообмена на теплообмен (т. е. $L u \ll 1)$ невелико. Кривые для обоих начальных градиентов температуры почти на всем протяжении параллельны друг другу. Несовпадение их обусловлено, очсвидно, изменением тепловых коэффициентов в зависимости от температуры. Поэтому опыты с материалами этой группы также не требуют минимальных градиентов начальных температур.

3. Изменение коэффициентов тепло- и температуропроводности с повышением влажности зависит от начального градиента температуры (пено- и газокукермит) (фиг. 18, г, д).

Коэффициент температуропроводности при малом начальном градиенте температуры сначала немного уменьшается (примерно до $10-15 \%$ весовой влажности) и в дальнейшем остается практически постоянным. Коэффициент теплопроводности при малом градиенте температуры увеличивается с повышением влажности практически по линейному закону. Кривая зависимости коэффициента температуропроводности от влажности при бо́льшем градиенте температуры имеет иной характер. Здесь происходит сначала увеличение и после $w_{\text {в }}=15-20 \%$ - постепенное уменьшение и приближение к нижней кривой (кривая при малом градиенте). Так же и коэффициент теплопроводности растет в этот период более интенсивно, а после указанных пределов темп возрастания $\lambda$ становится аналогичным темпу возрастания при малом градиенте температуры. Таким образом, при работе с материалами этой группы весьма важно правильно выбрать начальный градиент температуры. При малом градиенте (0,8 град/см) заметного перемещения влаги не возникает в силу сравнительно небольшого значения $L u$ (поле влажности отстает от поля температур в значительной мере). Но уже при $\nabla t \approx 8$ град/см возникает некоторое перемещение влаги при теплообмене, хотя градиенты температур и исчезают достаточно быстро.

Выше рассмотрены три группы материалов, различно реагирующие на величину начального градиента температуры при определении зависимости тепловых коэффициентов от влажности. Возникает вопрос, каковы градиенты температур в ограждающих конструкциях из этих материалов в натурных условиях? Если они находятся в пределах, при 

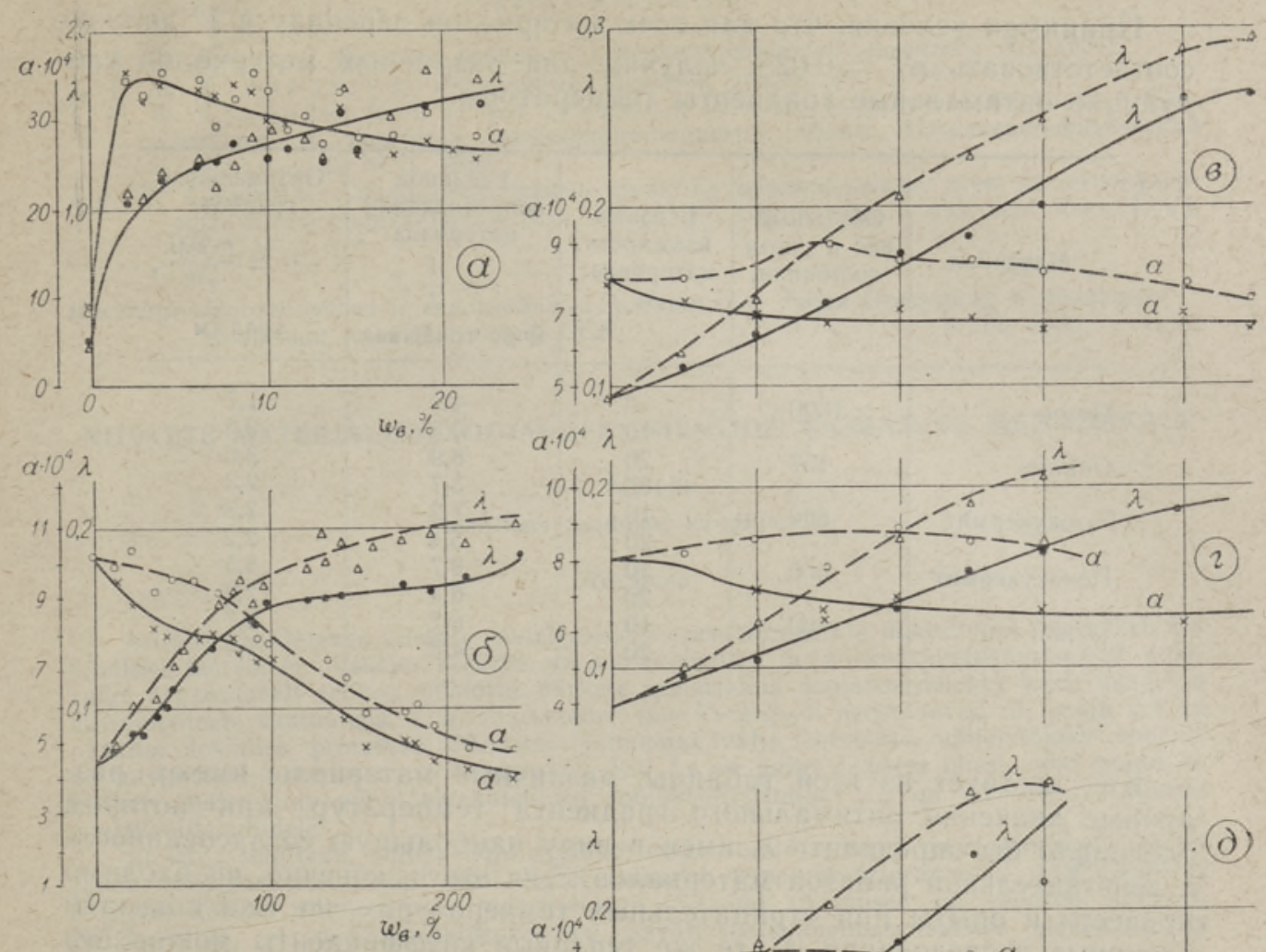

Фиг. 1. Зависимость коэффициентов температуро- и теплоіроводности $\left[a=f_{1}(w)\right.$ н $\left.\lambda=f_{2}(w)\right]$ для:

$a-$ песка $\left(\gamma=1600 \mathrm{\kappa r} / \mathrm{m}^{3}\right)$;

б - опилок $\left(\gamma=157 \mathrm{kr} / \mathrm{m}^{3}\right)$;

в - газокукермитӓ $(\gamma=600$ $\left.\mathrm{Kr} / \mathrm{M}^{3}\right)$;

2 - пенокукермита $(\gamma=500$ $\left.\mathrm{Kr} / \mathrm{M}^{3}\right)$;

$\partial$ - пенокукермита $(\gamma=700$ $\left.\mathrm{\kappa r} / \mathrm{M}^{3}\right)$ при $\Delta t=2^{\circ}(\times \mathrm{o})$ и $\Delta t=20^{\circ}(\Delta)$.

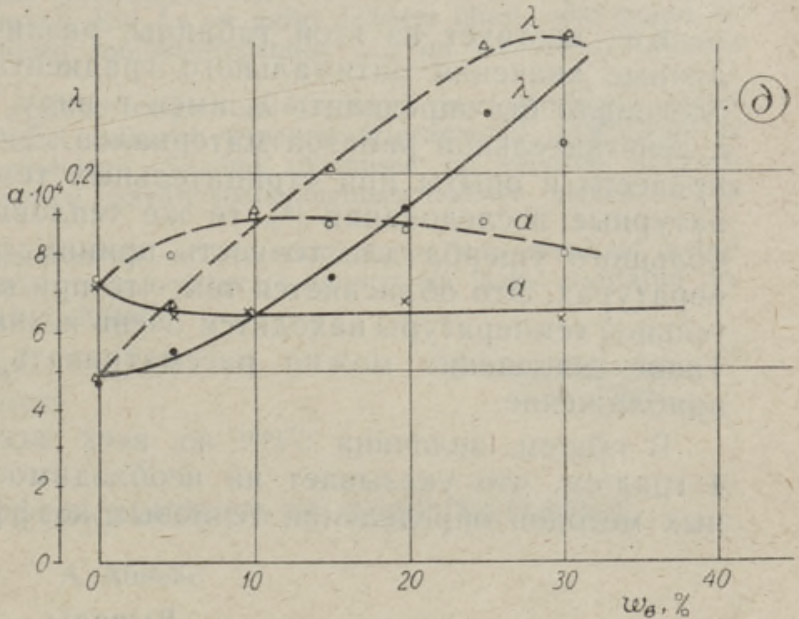

которых неизбежно возникает влагообмен при теплообмене, то при определении тепловых коэффициентов для проектирования нет необходимости добиваться более низких градиентов температуры, чтобы избавиться от влияния влагообмена, поскольку в таком случае лабораторные определения должны проводиться в условиях, как можно точнее отражающих действительную работу материалов. Для научных целей же определение тепловых коэффициентов при малых градиентах температуры представляет значительный интерес в любом случае.

Для более наглядного сравнения ограждающих конструкций из различных материалов необходимо рассматривать их в масштабе термического сопротивления слоев конструкций. Например, для климатических условий гор. Таллина, где расчетный перепад температуры между внутренним и наружным воздухом составляет $40^{\circ}$, требуемое сопротивление наружных стен теплопередаче $R_{0}^{\text {тp }}=1,0 \mathrm{~m}^{2}$ час град/ккал

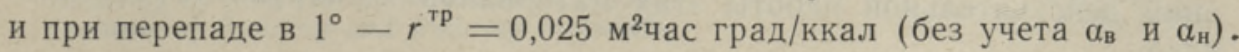


Принимая условия, что для всех материалов перепаду в $1^{\circ}$ должно соответствовать $r^{\text {тр }}=0,025$, получим для различных материалов следующие оптимальные градиенты температуры:

\begin{tabular}{|c|c|c|c|c|}
\hline Материал & $\begin{array}{c}\text { Объемный } \\
\text { вес в сухом } \\
\text { состоянии, } \\
\text { кг } / \mathrm{M}^{3}\end{array}$ & $\begin{array}{c}\text { Весовая } \\
\text { влажность } \\
\text { материала, } \\
\%\end{array}$ & $\begin{array}{c}\text { Удельное } \\
\text { сопротивление } \\
\text { материала } \\
r=\frac{1}{\lambda}, \\
\text { мчас град/ккал }\end{array}$ & $\begin{array}{l}\text { Oптимальный } \\
\text { градиент } \\
\nabla t=\frac{r \cdot 100}{r^{\text {тр }}}, \\
\text { град/см }\end{array}$ \\
\hline $\begin{array}{l}\text { Песок } \\
\text { Опилки } \\
\text { Газокукермит } \\
\text { Пенокукермит } \\
\text { То же }\end{array}$ & $\begin{array}{r}1600 \\
157 \\
600 \\
500 \\
700\end{array}$ & $\begin{array}{r}0 \\
10 \\
20 \\
150 \\
10 \\
20 \\
10 \\
20 \\
10 \\
20\end{array}$ & $\begin{array}{l}4,2 \\
0,8 \\
8,9 \\
5,7 \\
7,2 \\
5,4 \\
8,7 \\
6,4 \\
6,7 \\
4,8\end{array}$ & $\begin{array}{l}1,7 \\
0,3 \\
3,6 \\
2,3 \\
2,9 \\
2,2 \\
3,5 \\
2,6 \\
2,7 \\
1,9\end{array}$ \\
\hline
\end{tabular}

Как явствует из этой таблицы, различные материалы имеют различные значения оптимального градиента температур, при котором следовало бы определять $\lambda$, имея в виду наибольшую согласованность с действительной работой материалов. Для этого, конечно, необходимо провести и опыты при отрицательных температурах, но, как показади натурные исследования $\left.{ }^{4}\right]$, те же тепловые коэффициенты можно без большого ущерба для точности принимать и при отрицательных температурах. Это объясняется тем, что при нашем климате в зоне отрицательной температуры находится очень незначительная часть ограждения. Такое допущение можно рассматривать, конечно, лишь как первое приближение.

В общем, величина $\nabla t^{\text {onт }}$ во всех исследуемых материалах ниже 4 град/см, что указывает на необходимость применения нестационарных методов определения тепловых коэффициентов.

\section{Выводы}

1. Разработаны некоторые вопросы методики исследования тепловых коэффициентов влажных материалов (время выдерживания образца, проведение опытов при различных начальных градиентах температуры).

2. Получены зависимости коэффициентов тепло- и температуропроводности от влажности для газо- и пенокукермита, опилок и песка при двух начальных градиентах температуры. Установлено, что по характеру кривых эти материалы разделяются на три группы с точки зрения влияния влагообмена на теплообмен.

3. Установлены оптимальные начальные градиенты температуры при лабораторных определениях тепловых коэффициентов влажных материалов для получения данных, наиболее соответствующих условиям действительной работы этих материалов в наружных ограждения $\mathrm{x}$. 


\title{
П И Т Е Р А Т У Р А
}

1. А. В. Л ков, Явления переноса в капиллярно-пористых телах, М., 1954.

2. Г. М. Кондратьев, Регулярный тепловой режим, М., 1954.

3. М. Ф. Казанский, А. Н. Куландина, Влияние форм связи влаги на теплоперенос в типнчных капиллярно-пористых телах, Инженерно-физический журнал, т. 2, № 5, 1959.

4. А. Э. Алумяэ, Тепло-влажностные свойства крупноблочных стен из пенокукермита и пеносиликальцита, Изв. АН ЭССР. Серия техн, и физ. мат. наук, т. VI, 1957, № 1 .

Ннститут строительства и строительных материалов Академии наук Эстонской ССР
Поступила в редакцию

8. IV 1960

\section{NIISKETE MATERJALIDE SOOJAKOEFITSIENTIDE MÄARRAMISE METOODIKAST}

\author{
A. Alumäe, \\ tehniliste teaduste kandidaat
}

Resümee

Artiklis käsitletakse niiskete materjalide soojakoefitsientide määramise iseärasusi. On kindlaks tehtud, et niisketes kehades on soojavahetus- ja niiskusvahetusprotsessid omavahel orgaaniliselt seotud, mistōttu niiskete materjalide soojakoefitsiente tuleb vaadelda ekvivalentsete suurustena, s. o. suurustena, mis üheaegselt peegeldavad nii sooja kui ka niiskuse levimise protsesse. Niiskuse potentsiaalivälja inertsuse väljendajaks soojuse potentsiaalivälja suhtes on kriteerium $L u$. Kui $L u$ on palju väiksem ühest, võib saada ka niiskete materjalide puhul ekvivalentsed soojakoefitsiendid, mis on lähedased tōelistele soojakoefitsientidele.

Et välja selgitada, millist mõju avaldab temperatuurigradiendi muutus niiskete materjalide soojakoefitsientidele, tehti kahel erineval temperatuurigradiendil $\left(0,8^{\circ} \mathrm{C} / \mathrm{cm}\right.$ ja $8^{\circ} \mathrm{C} / \mathrm{cm}$ ) katseid mitmesuguste materjalidega. Saadud tulemused on esitatud joonisel. Neist nähtub, et niiskusvahetusprotsessi osavōtt soojavahetusprotsessist oleneb $L u$ ja temperatuurigradiendi suurusest.

Et määrata soojakoefitsiente laboratoorselt sellistes tingimustes, mis vastaksid materialide olukorrale piirdekonstruktsioonis, on katsetatavate materjalide jaoks arvutatud nn. optimaalsed temperatuurigradiendid katsekehas.

Eesti NSV Teaduste Akadeemia

Ehituse ja Ehitusmaterjalide Instituut
Saabus toimetusse

8. IV 1960

\section{INVESTIGATION OF HEAT CONDUCTIVITY OF MOIST MATERIALS}

\section{A. Alumäe}

\section{Summary}

This paper refers to some specific questions of the determination of heat conductivity of moist materials in laboratory. According to the view that in moist materials thermal conductance is connected with the migration of moisture, the values of thermal conductivity must be regarded as equivalent values. The criterion $L u$ shows the ratio of inertia of the field of moisture potential to the field of the thermal potential. If $L u$ is much less than one, one gets values of thermal conductivity that are almost identical with the actual values.

In order to find out the influence of the temperature gradient on the values of thermal conductivity of moist materials, the investigations were carried out at two temperature gradients $\left(0.8^{\circ} \mathrm{C} / \mathrm{cm}\right.$ and $\left.8^{\circ} \mathrm{C} / \mathrm{cm}\right)$. The results are presented in diagrams. The participation of migration of moisture in heat transfer depends on the values of $L u$ and on the temperature gradient.

In order to make a laboratory determination of heat conductivity in the conditions which best represent the conditions in real structures, the determination must be carried out at a temperature gradient which is optimal for the given material (Table 1). 